\title{
UMA ANÁLISE DA PRODUÇÃO ACADÊMICA BRASILEIRA SOBRE EDUCAÇÃO PROFISSIONAL E TECNOLÓGICA NA PERSPECTIVA POLITÉCNICA
}

\author{
AN ANALYSIS IN THE BRAZILIAN ACADEMIC PRODUCTION ABOUT THE PROFESSIONAL \\ AND TECHNOLOGICAL EDUCATION IN A POLYTECHNIC PERSPECTIVE \\ UN ANÁLISIS DE LA PRODUCCIÓN ACADÉMICA BRASILEÑA SOBRE EDUCACIÓN \\ PROFESIONAL Y TECNOLÓGICA EN LA PERSPECTIVA POLITÉCNICA
}

Karla Rodrigues Mota

E-mail: karla mota@msn.com Instituto Federal de Educação, Ciência e Tecnologia de Goiás - Campus de Anápolis - GO

Bolsista da Fundação de Amparo à Pesquisa do Estado de Goiás - FAPEG

Cláudia Helena dos Santos Araújo

E-mail: helena.claudia@gmail.com Instituto Federal de Educação, Ciência e Tecnologia de Goiás

Bruno Gonçalves dos Santos E-mail: brunodrops@hotmail.com Secretaria de Estado de Educação do Mato Grosso

\section{RESUMO}

O objetivo deste trabalho é apresentar o levantamento das produções acadêmicas brasileiras que versaram sobre a Educação Profissional e Tecnológica (EPT) na perspectiva politécnica, atentando às inter-relações que inferem nesta temática bem como os desafios à ela concernentes. Para tanto, fundamentado em Sánchez Gamboa (2012), Triviños (1987), Fazenda (2000) e Medeiros Neta (2016), foi realizado um estudo bibliográfico de caráter exploratório no Portal de Periódico CAPES, utilizando os descritores: Educação Profissional e Tecnológica; Formação Omnilateral; Escola Unitária; Educação Politécnica e Trabalho como Princípio Educativo, sendo considerados os artigos publicados entre os anos de 2010 e 2017. Os resultados de tais publicações destacam a potencialidade da Educação Profissional atuar como instrumento de emancipação humana, contudo evidenciam a escassez de estudos que debrucem sobre os Cursos Técnicos ofertados pelos Institutos Federais de Educação, Ciência e Tecnologia.

PALAVRAS-CHAVE: Escola Unitária. Educação Profissional e Tecnológica. Trabalho.

\section{ABSTRACT}

The present study is aimed to raise the brazilian academic productions which is about the professional and technological education in the polytechnic perspective, looking to the inter relations like a challenge. Based on Sánches Gamboa (2012), Triviños (1987), Fazenda (2000), e Medeiros Neta (2016), it was done a bibliographic exploratory study in the CAPES Periodicals Portal, using the descriptors: Professional and Technological Education; Formation Omnilateral; Unitarian school; Polytechnic Education e Work as Educational Principle, the articles published in the 2010 and 2017 were all considered. The result about the publications helps to show how the Professional Education acts as an instrument in the human emancipation, however, also shows the lack os study about the Technical Courses offered by Federal Institutes of Education, Science and Technology.

KEYWORDS: Unitary School. Professional and Technological Education. Work. 


\section{RESUMEN}

El objetivo de este trabajo es presentar el levantamiento de las producciones académicas brasileñas que versaron sobre la Educación Profesional y Tecnológica (EPT) en la perspectiva politécnica, atentando a las interrelaciones que inferen en esta temática así como los desafios a ella concernientes. Para ello, fundamentado en Sánchez Gamboa (2012), Triviños (1987), Hacienda (2000) y Medeiros Neta (2016), se realizó un estudio bibliográfico de carácter exploratorio en el Portal de Periódico CAPES, utilizando los descriptores: Educación Profesional y Tecnológica; Formación Omnilateral; Escuela Unitaria; La educación politécnica y el trabajo como principio educativo, siendo considerados los artículos publicados entre los años 2010 y 2017. Los resultados de dichas publicaciones destacan la potencialidad de la Educación Profesional actuar como instrumento de emancipación humana, sin embargo evidencian la escasez de estudios que debrucen sobre los Cursos Técnicos ofertados por los Institutos Federales de Educación, Ciencia y Tecnología.

PALABRAS-CLAVE: Até três palavras-chave separadas por ponto. Escuela Unitaria. Educación Profesional y Tecnológica. Trabajo.

\section{INTRODUÇÃO}

O presente artigo tem por objetivo conhecer as temáticas discutidas pela comunidade acadêmica acerca da Educação Profissional e Tecnológica (EPT) no Brasil dentro da perspectiva politécnica. Trata-se de um desdobramento inicial de uma pesquisa em desenvolvimento intitulada “A travessia: a formação omnilateral no Curso Técnico Integrado em Química do Instituto Federal de Educação, Ciência e Tecnologia de Goiás câmpus Anápolis" do Mestrado Profissional em Educação Profissional e Tecnológica (ProfEPT) cujo início deu-se no ano de 2017 no Instituto Federal de Educação, Ciência e Tecnologia de Goiás - Câmpus Anápolis.

A Educação Profissional e Tecnológica pode orientar-se pelo prisma da escola politécnica que, fundamentada no trabalho como princípio educativo, visa promover a superação da sociedade alienada pelo capital bem como garantir a formação omnilateral dos sujeitos. Por mais que o termo politecnia sugira a ideia de múltiplas técnicas, Saviani (2007) o utiliza e o defende como sinônimo do domínio de fundamentos e conceitos científicos essenciais aos ramos mais importantes da produção industrial moderna, refletindo uma proposta de educação que supre o sujeito não somente com a técnica específica e restrita à reprodução do trabalho manual, mas que permite, por meio da difusão do conhecimento historicamente acumulado, a compreensão do processo produtivo como um todo.

A formação omnilateral refere-se a uma concepção de formação humana que integra as várias dimensões da vida, buscando desenvolver no indivíduo as suas potencialidades de caráter físico, mental, cultural, político e científico-tecnológico. Ou seja, trata-se de possibilitar "um desenvolvimento total, completo, multilateral, em todos os sentidos, das faculdades e das forças produtivas, das necessidades e da capacidade da sua satisfação" (MANACORDA, 2007, p. 87).

\begin{tabular}{l|l|l|l|l|l|} 
(C) Revista Triângulo & Uberaba, Minas Gerais & v.12 & n.1 & p. $162-180$ & 2019
\end{tabular}




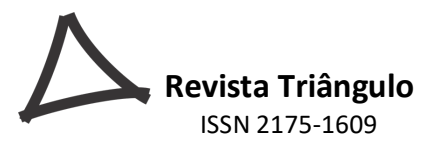

Gramsci (1982), em defesa de uma educação que viabilize o desenvolvimento das potencialidades humanas, propõe a Escola Unitária na perspectiva de superar a sociedade de classes e a escola que tradicionalmente segrega os indivíduos, destinando grande parte ao desempenho de uma atividade técnica-industrial enquanto seleciona alguns para a carreira universitária. A Escola Unitária gramsciana aponta para uma proposta educativa em que se "equilibre equanimemente o desenvolvimento da capacidade de trabalhar manualmente (tecnicamente, industrialmente) e o desenvolvimento das capacidades de trabalho intelectual" (p. 118).

Aproximando dos princípios da omnilateralidade, os Institutos Federais de Educação, Ciência e Tecnologia buscam ofertar uma Educação Profissional que integre harmonicamente trabalho, ciência, cultura e tecnologia. Pauta-se na compreensão do sujeito como um ser histórico e social e da escola como espaço com potencialidade para a formação de "profissionais-cidadãos" omnilaterais (IFG, 2012).

O Ensino Médio Integrado à Educação Profissional e Tecnológica (EPT), assim como ofertado nos Institutos Federais, deve ser compreendido como um mecanismo que permite desenvolver integralmente o indivíduo. Nesta perspectiva, compreende-se que cabe à escola não apenas difundir a técnica necessária para o desempenho de uma profissão, mas, principalmente, conscientizar o sujeito de que a luta pelo trabalho ocorre "no campo mais amplo da sociedade" (FRIGOTTO; CIAVATTA; RAMOS, 2012b, p. 15), permitindo-o entender que seu processo formativo é também um movimento emancipatório.

Legalmente, a integração da EPT à Educação Básica de nível médio formalizou-se no Brasil em 2004, após o Decreto n. 5.154 que regulamenta o $\S 2^{\circ}$ do art. 36 e os arts. 39 a 41 da Lei $n^{\circ}$ 9.394/1996. Tal decreto autorizou a oferta, mediante matrícula única, da formação técnica concomitante à Educação Básica.

De acordo com Moura (2007), este decreto não expressa o real modelo da Escola Unitária, porém, assegura os princípios básicos para a sua posterior implementação. Ou seja, o Ensino Médio Integrado, ofertado pelos Institutos Federais de Educação, Ciência e Tecnologia, ainda não condiz totalmente com os pilares gramscianos, mas emerge e se constitui como uma "travessia", abrindo caminhos para posterior implantação de uma educação ainda mais próxima da formação omnilateral (FRIGOTTO; CIAVATTA; RAMOS, 2012a).

Neste contexto, coube a nós a função de fazer um levantamento da produção acadêmica brasileira sobre a Educação Profissional e Tecnológica na perspectiva politécnica, dialogar com os 
referenciais teóricos e inferir os seguintes questionamentos: Quais objetos de investigação instigam a reflexão da comunidade acadêmica brasileira quando o tema de pesquisa é a EPT politécnica? Existem estudos sobre a Educação Profissional ofertada pelos Institutos Federais de Educação, Ciência e Tecnologia? Quais os principais impasses observados para a implementação de uma EPT Politécnica e omnilateral? Quais as principais redes de publicação de artigos científicos quando o tema é EPT?

Tais indagações orientam os objetivos deste escrito, enquadrando esta produção como um estudo exploratório, que, segundo Triviños (1987), permite ao pesquisador "aumentar sua experiência em torno de determinado problema" (p. 109). Neste caso, buscaremos “mapear” a temática Educação Profissional e Tecnológica Politécnica bem como identificar os itens ainda não investigados ou que necessitam de maior aprofundamento pela comunidade acadêmica.

\section{REFERENCIAL TEÓRICO}

Marx (1996) define trabalho como uma "atividade orientada a um fim" pela qual o homem intervém conscientemente sobre a natureza objetivando suprir suas necessidades. O trabalho, portanto, se apresenta como um elemento intrínseco à todas as formas de organização social humanas e "através desta atividade, o homem vai produzindo as condições de sua existência, transformando a natureza e criando, portanto, a cultura e um mundo humano" (SAVIANI, 2003).

O "mosaico de sentidos" que assume a categoria trabalho é resultado e, ao mesmo tempo, elemento fundante das relações sociais consolidadas ao longo do desenrolar histórico da humanidade. O vocábulo trabalho deve ser discutido para além de sua natureza semântica, teórica e epistemológica, sendo analisado, principalmente, dentro de uma dimensão histórico-social, ontológica e éticopolítica, a fim de afastar visões abstratas e sem relação com o seu espaço temporal (FRIGOTTO, 2009).

Diante de um prisma ontológico, compreende-se que o homem constitui-se como um ser que necessita, imprescindivelmente, trabalhar e educar para garantir a sua existência e perpetuar sua espécie. O trabalho, numa perspectiva imanente, é entendido como a modificação intencional da natureza pelo homem, ao passo que educação pode ser compreendida como a apropriação e perpetuação destes saberes pela posteridade (SAVIANI, 2007).

Segundo Antunes (2007), o trabalho apresenta-se como uma mediação de primeira ordem entre ser humano e natureza, constituindo-se de um instrumento por meio do qual o homem cria e se

\begin{tabular}{l|l|l|l|l|l} 
(C) Revista Triângulo & Uberaba, Minas Gerais & v.12 & n.1 & p. $162-180$ & 2019
\end{tabular}


(re)inventa visando produzir sua existência bem como se relacionar com os outros homens. No entanto, a emergência do modo de produção capitalista desenvolveu um sistema de metabolismo social no qual o trabalho, ao ser submetido ao capital, perde esta dimensão ontocriativa, tornando-se um instrumento de alienação e aprisionamento do trabalhador.

A alienação, neste sentido, é entendida como um processo no qual a consciência de homens e mulheres são capturadas, fazendo-os pensarem e "lerem o mundo" a partir da perspectiva do capital. Assim, tanto a relação de "processos de trabalho-trabalhador" quanto a de "produtos do trabalhotrabalhador", tornam-se relações "estranhadas", fazendo com que o homem não se aproprie, nem reconheça o trabalho como algo essencialmente seu (ANTUNES, 2007).

O advento capitalista promoveu a separação do trabalho manual e do trabalho intelectual, ou seja, separou o sujeito que "pensa" do sujeito que "executa", produzindo um trabalhador cindido. A escola, diante desta nova configuração social, também se divide em duas: uma escola de formação geral destinada à classe dominante que visa desenvolver todas as potencialidades mentais dos sujeitos e uma escola profissionalizante cujo objetivo é fomentar o indivíduo exclusivamente com a técnica necessária ao manejo das atividades industriais desenvolvendo tão simplesmente suas habilidades operatórias (SAVIANI, 2007).

Trata-se de um modelo de educação que distribui os conteúdos conforme a classe social que o sujeito ocupa. Assim, à classe proletária basta apenas ensinar as técnicas necessárias ao desempenho de uma função ao passo que para a elite ensina-se grande parte da ciência historicamente produzida pela humanidade (RAMOS, 2009).

Esta escola dual mantém os sujeitos estagnados em suas classes sociais, segregando, de um lado, os opressores, detentores dos meios de produção, e, de outro, os oprimidos, que meramente vendem sua força de trabalho. Por estar a serviço do capital, esta escola assegura a divisão da sociedade "em dois grandes campos inimigos, em duas grandes classes diretamente opostas: a burguesia e o proletariado" (MARX; ENGELS, 2008, p. 9).

Em objeção a esta escola fragmentada, Antônio Gramsci propõe a Escola Unitária, uma escola de cultura geral que prima por orientar os alunos na construção de sua maturidade, no alcance da criação intelectual e prática, ou seja, no pleno desenvolvimento das suas potencialidades de trabalho manual e intelectual. Trata-se, de uma proposta educativa que fomenta o sujeito com a estrutura necessária para optar autonomamente entre os estudos universitários e os estudos voltados para uma especialização profissional (GRAMSCI, 1982). 


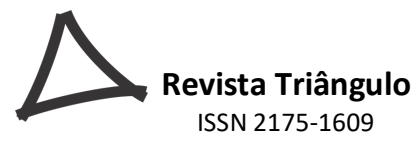

Os princípios da escola gramsciana estão presentes na concepção de educação politécnica e omnilateral, ou seja, numa formação que integre todas as dimensões da vida, dentre elas a científica, cultural e do trabalho, este último compreendido como uma característica ontológica da práxis humana (RAMOS, 2009). Vale ressaltar que a politecnia, longe de ser aceita como sinônimo de múltiplas técnicas é aplicada "na direção da superação da dicotomia entre trabalho manual e trabalho intelectual, entre instrução profissional e instrução geral (SAVIANI, 2003, p. 136).

A Educação Politécnica encontra-se fundamentada no trabalho, na ciência e na cultura, objetivando fornecer aos indivíduos os conhecimentos e a cultura historicamente produzidos pela humanidade, garantindo a compreensão dos princípios científico-tecnológicos e históricos da produção da existência humana moderna, habilitando o ser para o exercício autônomo e crítico das profissões. Este modelo de ensino busca, a partir do desenvolvimento do capitalismo e de sua crítica, superar a proposta burguesa de educação, incentivando a transformação estrutural da sociedade (RAMOS, 2009).

\section{MATERIAIS E MÉTODOS}

Por muito tempo, tentou-se adequar as investigações inseridas no campo do ensino e educação aos mecanismos das ciências físicas e naturais, tentando isolar variáveis e promover, assim, uma análise precisa e objetiva. Diante deste prisma, acreditava-se na possibilidade de decompor os fenômenos, promover uma análise acurada e, por fim, quantificar os processos educativos. Deste modo, por meio da observação e exame das "partes", seria possível alcançar a compreensão total do fenômeno estudado (LUDKE; ANDRÉ, 1986). Todavia, uma pesquisa sobre ensino e educação, por encontrar-se situada dentro das ciências humanas e sociais, não comporta a utilização de técnicas puramente mecânicas na sua análise.

Frente a esta dificuldade, as formas de se estudar os fatores que influenciam os processos educativos foram redefinidas, compreendendo "a educação como um campo de pesquisas com características próprias" (SÁNCHEZ GAMBOA, 2012, p. 131) que recebe influência multidisciplinar, principalmente das teorias filosóficas, sociológicas, pedagógicas e históricas.

Este escrito, inserido no campo do ensino e educação, constitui-se de uma pesquisa bibliográfica de caráter exploratório que servirá de embasamento e norte para uma investigação a ser desenvolvida no Mestrado Profissional em Educação Profissional e Tecnológica do Instituto Federal de Educação, Ciência e Tecnologia de Goiás - Câmpus Anápolis. Caracteriza-se como uma pesquisa

\begin{tabular}{l|l|l|l|l|l|} 
(C) Revista Triângulo & Uberaba, Minas Gerais & v.12 & n.1 & p. 162 - 180 & 2019
\end{tabular}


bibliográfica, pois se fundamenta "a partir do registro disponível, decorrente de pesquisas anteriores" e exploratória na medida em que busca "levantar informações sobre determinado objeto, delimitando assim um campo de trabalho, mapeando as condições de manifestações desse objeto" (SEVERINO, 2007, p. 123).

Entende-se que não se deve descartar a aparência fenomênica do objeto, mas sim de conceber esta etapa como um nível de realidade, cuja apropriação é necessária para um posterior aprofundamento e compreensão do todo. Deste modo, o conhecimento formulado a posteriori será obtido através da análise e síntese do objeto, onde o pesquisador reproduzirá no campo do pensamento, ou seja, no campo ideal o objeto investigado (PAULO NETTO, 2011).

Fazenda (2000) apresenta a importância desta etapa de apropriação do estado da arte em uma pesquisa. Neste estágio o pesquisador defronta-se com inúmeras obras sobre o seu tema de investigação, o que pode carecer de uma "ordenação em subtemas", mas principalmente indicar "quais os itens a serem melhor explorados" (p. 17). Comungando de tais compreensões, Triviños (1987) afirma que

O processo de avaliação do material bibliográfico que o pesquisador encontra lhe ensinará até onde outros investigadores têm chegado em seus esforços, os métodos empregados, as dificuldades que tiveram de enfrentar, o que pode ser ainda investigado etc. Ao mesmo tempo, irá avaliando seus recursos humanos e materiais, as possibilidades de realização de seu trabalho, a utilidade que os resultados alcançados podem emprestar a determinada área do saber e da ação (TRIVIÑOS, 1987, p. 100).

Isto posto, para a elaboração deste escrito foi realizada uma revisão de literatura fundamentada em Sánchez Gamboa (2012), Triviños (1987), Fazenda (2000) e Medeiros Neta (2016) com o objetivo de apreender a produção de conhecimento existente acerca da temática EPT na perspectiva politécnica bem como identificar "estratégias de pesquisa como possíveis categorias de análise" (SÁNCHEZ GAMBOA, 2012, p. 116).

Tal levantamento foi executado no Portal de Periódicos ${ }^{i}$ da Coordenação de Aperfeiçoamento de Pessoal de Nível Superior (CAPES) sendo pesquisados artigos publicados entre os anos de 2010, data de criação do Curso Técnico Integrado em Química do IFG câmpus Anápolisii, e outubro de 2017, data de início desta pesquisa, fazendo o uso dos descritores:

a) Educação Profissional e Tecnológica;

b) Formação Omnilateral;

c) Escola Unitária; 
d) Educação Politécnica; e

e) Trabalho como Princípio Educativo.

A pesquisa foi realizada na área de busca avançada do Portal de Periódicos CAPES e, assim como Medeiros Neta (2016), utilizou-se em cada descritor o recurso de aspas duplas como operador de pesquisa visando "reduzir o quantitativo de dados considerados relevantes para a construção da pesquisa e, por consequência, desconsiderar os dados irrelevantes" (p. 52). Por meio de tal recurso, a busca recolheu apenas os artigos que apresentaram, no título e/ou no corpo do texto, o termo assim como se encontra expresso no descritor. Por exemplo, ao digitar no campo de busca o descritor “Trabalho como Princípio Educativo" (com aspas duplas) somente serão selecionados os artigos em que às quatro palavras (trabalho, como, princípio e educativo) estejam assim reunidas e nesta ordem, sendo descartados os artigos que contenham apenas o termo trabalho ou educativo.

Em seguida, buscando um maior refinamento dos dados, procedeu-se com a leitura dos resumos dos artigos, sendo descartados os que não discutiam a temática da Educação Profissional e Tecnológica. Como resultado, obteve-se um quantitativo de 62 artigos.

Frente à grande quantidade de trabalhos encontrados, tornou-se interessante, a realização de um estudo compilatório ou classificatório (FAZENDA, 2000, p. 17). Para tanto, os artigos encontrados para cada descritor foram dispostos em planilhas utilizando como instrumento o Microsoft Office Excel, o que permitiu "uma reorganização e controle dos dados coletados" (MEDEIROS NETA, 2016, p. 52).

Nessa sistematização dos resultados encontrados foram destacadas as seguintes informações dos artigos: Título, Nome do(s) autor(es), Nome da revista, Ano de publicação, Qualis da revista em Ensino e/ou educação, Temática Discutida pelo artigo (feita através da leitura do resumo ou, quando necessário, do artigo por completo) e Observações. A sistematização dos dados viabilizou uma análise mais eficaz da temática bem como uma interlocução entre as pesquisas já realizadas.

\section{ANÁLISE DOS DADOS E RESULTADOS}

A análise do universo bibliográfico produzido nos últimos oito anos indica que comunidade acadêmica brasileira vem intensificando suas produções frente a temática Educação Profissional e Tecnológica (EPT). Fazendo a compilação dos 62 artigos encontrados em subtemas (FAZENDA, 2000), percebeu-se que os pesquisadores centraram suas reflexões sobre os seguintes objetos de estudo e pesquisa ${ }^{\text {iii: }}$ 
a) Docência em Educação Profissional e Tecnológica;

b) Concepção da Categoria Trabalho;

c) Políticas Públicas em EPT;

d) Educação Profissional como possibilidade de transformação da sociedade;

e) Programa Nacional de Integração da Educação Básica com a Educação Profissional na Modalidade de Educação de Jovens e Adultos (PROEJA); e

f) Legislação da Educação Profissional.

Dentre as produções, foi possível captar uma preocupação dos pesquisadores sobre a possibilidade e necessidade de se promover uma Educação Profissional que sirva de instrumento para a transformação e emancipação dos sujeitos na dimensão política e pedagógica, visto que, dos 62 artigos encontrados, 23 debruçavam-se sobre esta problematização, conforme representado na Tabela 1. De modo geral, tais produções pautavam-se na compreensão do homem como um ser do trabalho, capaz de transformar constantemente a natureza e o meio em que vive, carecendo, portanto, de um projeto educativo que revele essa sua essência.

Tabela 1 - Distribuição dos subtemas discutidos pela comunidade acadêmica.

\begin{tabular}{c|c}
\hline Subtemas & Quantidade \\
\hline Docência em EPT & 11 \\
\hline Políticas públicas & 13 \\
\hline Concepção de trabalho & 11 \\
\hline Legislação & 2 \\
\hline Currículo & 7 \\
\hline PROEJA & 5 \\
\hline Educação Profissional como transformação da sociedade & 23 \\
\hline
\end{tabular}

Fonte: Elaboração própria, a partir dos dados disponíveis no Portal (2017).

Em relação a um dos objetivos deste trabalho, que era verificar existência de pesquisas sobre a Educação Profissional ofertada pelos Institutos Federais de Educação, Ciência e Tecnologia, notouse que 20 artigos discorriam sobre tal lócus educacional, correspondendo à cerca de $31,3 \%$ dos dados encontrados.

Partindo da compreensão de que as produções científicas são uma "reprodução, no plano do pensamento, do movimento real do objeto" (PAULO NETTO, 2011, p. 25), pode-se justificar esta 


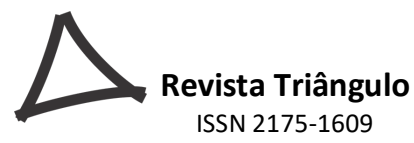

ISSN 2175-1609

quantidade significativa de produções sobre os Institutos Federais como um reflexo do recorte temporal deste levantamento bibliográfico, cujo marco inicial foi o ano de 2010, dois anos após a promulgação da Lei n. ${ }^{0} 11.892$, de 29 de dezembro de 2008, a qual institui a Rede Federal de Educação Profissional e Tecnológica e cria os Institutos Federais de Educação, Ciência e Tecnologia.

Ainda sobre este viés de explanações, percebeu-se que os trabalhos que perpassavam suas análises pelos Institutos Federais de Educação, Ciência e Tecnologia versavam sobre as especificidades e singularidades da docência em EPT e, principalmente, sobre a função emancipadora de tais instituições, as quais se configuram como "uma possibilidade para os filhos da classe trabalhadora" (MOURA, 2007, p. 21). Contudo, torna-se importante ressaltar que, mesmo com tantas produções sobre os referidos institutos, ainda são escassas as pesquisas que estudam a fundo e em especificidade os seus Cursos Técnicos de Educação Profissional, visto que foram encontrados apenas dois trabalhos que debruçavam sob esta perspectiva, sendo eles:

1. “A produção de subjetividades docentes na educação profissional e tecnológica: em ação o dispositivo currículo" (FREITAS; OLIVEIRA, 2015) que investigou o curso Técnico de Manutenção e Suporte em Informática na modalidade PROEJA do Instituto Federal Sul-riograndense;

2. "O papel do Instituto Federal de Educação, Ciência e Tecnologia (IFRN) para a qualificação e empregabilidade: um estudo dos egressos do curso de informática do IFRN em Currais Novos/RN" (VIEIRA; SILVA; GOMES, 2011) que investigou o Curso Técnico de Nível Subsequente em Informática do Instituto Federal do Rio Grande do Norte.

Este levantamento bibliográfico permitiu perceber que as produções sobre a Educação Profissional e Tecnológica tendem a apresentar considerável grau de elaboração, discussão e embasamento teórico, dado que $94 \%$ dos artigos selecionados encontram-se publicados em revistas com conceitos A1, A2, B1 ou B2 no Qualis-Periódicos ${ }^{\mathrm{iv}}$ da CAPES nas áreas de Ensino e/ou Educação.

Os 62 artigos selecionados encontram-se distribuídos em 29 revistas acadêmicas, dentre as quais, conforme demonstra o Gráfico 1, destacou-se como periódico de maior publicação na temática Educação Profissional e Tecnológica a Revista Holos, vinculada ao Instituto Federal de Educação, Ciência e Tecnologia do Rio Grande do Norte, sendo responsável por publicar 23 artigos, representando em torno de $37 \%$ das produções encontradas, fator que pode ser justificado pela existência do Mestrado Acadêmico em Educação Profissional sediado em tal instituição. 
Gráfico 1 - Distribuição das publicações por periódico.

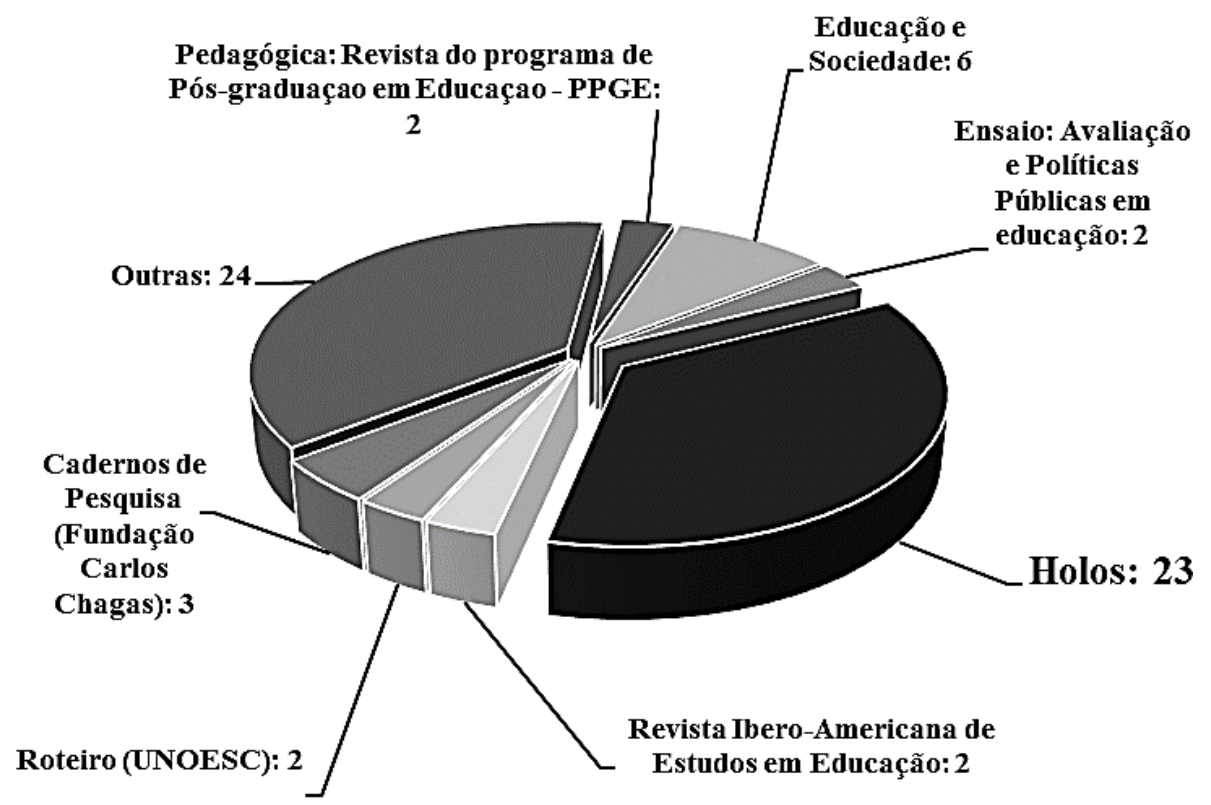

Fonte: Elaboração própria, a partir dos dados disponíveis no Portal (2017).

Todavia, quando se analisa as produções por região brasileira percebe-se que a região sudeste é a que apresenta maior quantitativo de artigos publicados dentro desta temática, sendo responsável por, aproximadamente, $41 \%$ das publicações, conforme evidenciado pela Tabela 2 . A expressividade de produções publicadas na região sudeste pode se configurar como reflexo do quantitativo de revistas acadêmicas presentes em tal localidade, visto que das 29 revistas encontradas, 17 estão sediadas em tal região do país.

Tabela 2 - Distribuição das publicações por região de origem do periódico.

\begin{tabular}{c|c|c}
\hline Região & Quantidade de Revistas & Quantidade de Artigos Publicados \\
\hline Sudeste & 17 & 26 \\
\hline Sul & 8 & 10 \\
\hline
\end{tabular}

$\mathbf{v . 1 2}$ 


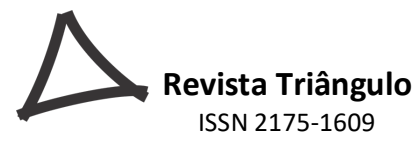

ISSN 2175-1609

\begin{tabular}{c|c|c}
\hline Centro-Oeste & 3 & 3 \\
\hline Norte & 0 & 0 \\
\hline Nordeste & 1 & 23 \\
\hline Total & $\mathbf{2 9}$ & $\mathbf{6 2}$ \\
\hline
\end{tabular}

Fonte: Elaboração própria, a partir dos dados disponíveis no Portal (2017).

Ainda que alguns resultados sejam provisórios, tais pesquisas evidenciam alguns impasses que dificultam o desenvolvimento e consolidação da EPT no Brasil. Os estudos demonstram que os docentes em EPT apresentam fragilidades no trabalho pedagógico (CARVALHO; SOUZA, 2014; CRUZ; VITAL, 2014; GANDRA; FIGUEIREDO, 2014; FARTES; SANTOS, 2011; LIMA; SILVA, 2014; SHIROMA; LIMA FILHO, 2011; OLIVEIRA, 2016; RODRIGUES, 2016; SILVA, 2016; MACHADO, 2011a, 2011b); salientam que os documentos normativos e legislativos que normatizam esta modalidade de ensino defendem diferentes concepções de EPT (AFONSO; GONZALEZ, 2016; FERRETI, 2011; OLIVEIRA, 2016; PEREIRA, 2015; RAMOS, 2016; RIBEIRO, 2012; SILVA, 2016; SILVA; CABRAL NETO, 2015; ZATTI; DONNER; JESUS, 2014); além de evidenciar que as políticas públicas voltadas para esta modalidade de educação estiveram - e estão - historicamente atreladas aos contextos produtivos brasileiros, deixando a EPT "a mercê" dos interesses do mercado (ARAÚJO; HYPÓLITO, 2016; CEZAR; FERREIRA, 2016; CIAVATTA, 2016; FERRARI, 2015; FOLGADO et al., 2016; GARIGLIO; BURNIER, 2012; LIMA; SILVA; SILVA, 2015; LIMA JUNIO; TAUCHEN, 2016; MELO; MOURA, 2016; MIRANDA, 2016; MOURA, 2013; NEIVA FILHO; VASCONCELLOS; SOUZA, 2015; OLIVEIRA; MATTA, 2017; RAMOS, 2016; SILVA, 2016).

A revisão de literatura também destacou a importância da Educação Profissional e Tecnológica ser fundamentada numa concepção de formação humana omnilateral e no trabalho enquanto princípio educativo; além de defender a Escola Unitária gramsciniana para o Ensino Médio em oposição à atual divisão existente entre escolas humanísticas e escolas técnicas.

\section{CONSIDERAÇÕES FINAIS}

Partindo do pressuposto que desde sua origem, o homem cria e recria condições de garantir a sua existência por meio do trabalho, elemento que lhe confere o caráter de ser social (ANTUNES, 2007), justifica-se a necessidade da Educação Profissional e Tecnológica assentar sobre os pilares da 
escola unitária gramsciana, visto que por meio deste ideário formativo o homem pode compreender as bases teóricas, científicas, históricas e tecnológicas que fundamentam a produção da existência humana moderna.

Todavia, para a sua implementação, esta modalidade da educação carece de estudos por parte da comunidade acadêmica que de posse de uma olhar crítico pode analisar com mais proximidade e clareza os resultados desse processo formativo, bem como as transformações que a formação para o trabalho podem acarretar ou não na sociedade.

A Educação Profissional quando se dá de forma integrada à Educação Básica permite que o sujeito desenvolva tanto suas capacidades práticas quanto as teóricas, possibilitando a apreensão da técnica e manuseio das ferramentas e equipamentos inerentes ao mundo do trabalho, ao passo que também garante a base teórica e científica que fundamenta a sua atividade específica.

Buscando aproximar estas reflexões dos resultados obtidos neste escrito, observa-se que as pesquisas brasileiras que se debruçaram sobre a Educação Profissional e Tecnológica (EPT) centraram suas reflexões, principalmente, sobre o potencial que a Educação Profissional tem em transformar a realidade da classe trabalhadora, visto que ao se dar de forma integrada à educação básica permitem aos seus alunos lerem o mundo do trabalho de forma menos influenciada pelo capitalismo. Relatam, ainda, que não há um consenso dentro dos documentos normativos e legislativos sobre a concepção de EPT e de formação omnilateral.

Conclui-se, também, que os estudos sobre esta modalidade de ensino ainda são incipientes, visto que dentro dos oito anos estudados, 2010-2017, foram encontrados apenas 62 artigos que discutem a EPT na perspectiva politécnica. Contudo, tais pesquisas apresentam uma qualidade acadêmica considerável, pois $94 \%$ destes artigos estão publicados em revistas com Qualis-Periódicos maior ou igual ao substrato de avaliação B2. Neste contexto, vale destacar, também, o papel da Revista Holos que atuou como relevante difusora de tais investigações, sendo o periódico com maior expressividade nesta investigação, visto que $37 \%$ dos estudos encontrados foram publicados no referido periódico.

Ao analisar as investigações sobre os Institutos Federais de Educação, Ciência e Tecnológica, percebemos a existência de estudos onde pôde-se depreender que ainda existe a necessidade de pesquisas que debrucem sobre os cursos técnicos integrados dos Institutos Federais de Educação, Ciência e Tecnologia, dado que tal instituição pública pode promover a emancipação do indivíduo e a superação do trabalho superexplorado. 


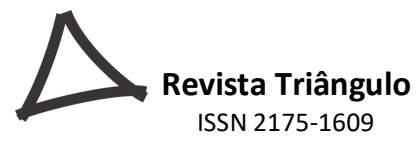

Isto posto, com base neste estudo bibliográfico, afirma-se que a temática da Educação Profissional e Tecnológica vêm sendo (ainda que timidamente) discutida nos periódicos brasileiros, evidenciando preocupação da comunidade acadêmica com esta perspectiva formativa, compreendida, assim como afirmando por Medeiros Neta (2016), tanto como uma "modalidade de ensino" quanto um "espaço de disputas políticas" (p, 54).

\footnotetext{
' O Portal de Periódicos CAPES, constitui-se de uma biblioteca virtual que reúne e disponibiliza grande parte da produção acadêmica nacional e internacional $<$ http://www.periodicos.capes.gov.br $>$.

ii Optou-se pelo ano de criação do Curso Técnico Integrado em Química do IFG câmpus Anápolis como marco temporal deste escrito, pois este é o objeto de investigação do projeto de pesquisa "A travessia: a formação omnilateral no Curso Técnico Integrado em Química do Instituto Federal de Educação, Ciência e Tecnologia de Goiás câmpus Anápolis" do Mestrado Profissional em Educação Profissional e Tecnológica (ProfEPT) que instigou a elaboração deste trabalho.

iii Alguns artigos versaram sobre dois ou mais objetos de estudo e pesquisa.

iv De acordo com o site da Plataforma Sucupira, "O Qualis-Periódicos é um sistema usado para classificar a produção científica dos programas de pós-graduação no que se refere aos artigos publicados em periódicos científicos. Tal processo foi concebido para atender as necessidades específicas do sistema de avaliação e é baseado nas informações fornecidas por meio do aplicativo Coleta de Dados. Como resultado, disponibiliza uma lista com a classificação dos veículos utilizados pelos programas de pós-graduação para a divulgação da sua produção". Disponível em: $<$ https://sucupira.capes.gov.br/sucupira/public/index.jsf $>$. Acesso 30 dez. 2017.
}

\section{REFERENCIAS}

AFONSO, Anthone Mateus Magalhães; GONZALEZ, Wania Regina Coutinho. Educação Profissional e Tecnológica: análises e perspectivas da LDB/1996 à CONAE 2014. Ensaio: aval. Pol. Públi. Educ., v. 24, n. 92, jul./set. 2016, p. 719-742. Disponível em: $<$ http://www.scielo.br/pdf/ensaio/v24n92/1809-4465-ensaio-24-92-0719.pdf $>$. Acesso 03 dez. 2017.

ANTUNES, Ricardo. Os sentidos do trabalho: Ensaio sobre a afirmação e a negociação do trabalho. São Paulo: Boitempo Editorial, 2007.

ARAÚJO, Jair Jonko; HYPÓLITO, Álvaro Moreira. Novos significados para educação profissional e tecnológica no instituto federal sul-rio-grandense: a política de criação dos institutos. Rev. Bras. de Pol. e Adm. da Educ, v. 32, n. 1, jan./abr. 2016, p. 247-265. Disponível em: $<$ http://seer.ufrgs.br/index.php/rbpae/article/view/62363/37748>. Acesso 03 dez. 2017.

BRASIL. Lei n. ${ }^{\circ}$ 11.892, de 29 de dezembro de 2008. Institui a Rede Federal de Educação Profissional, Científica e Tecnológica, cria os Institutos Federais de Educação, Ciência e Tecnologia, e dá outras providências. Disponível em: $<$ http://www.planalto.gov.br/ccivil_03/_ato2007-2010/2008/lei/111892.htm>. Acesso 30 dez. 2017.

. Decreto . $^{\circ} 5.154$, de 23 de julho de 2004. Regulamenta o $§ 2^{\circ}$ do art. 36 e os arts. 39 a 41 da Lei $n^{\circ}$ 9.394, de 20 de dezembro de 1996, que estabelece as diretrizes e bases da educação nacional, e dá outras providências. Disponível em: $<$ http://www.planalto.gov.br/ccivil_03/_ato20042006/2004/decreto/d5154.htm>. Acesso 30 dez. 2017. 
CARVALHO, Olgamir Francisco de; SOUZA, Francisco Heitor de Magalhães. Formação do docente da educação profissional e tecnológica no Brasil: um diálogo com as faculdades de educação e o curso de Pedagogia. Educação e Sociedade, v. 35, n. 128, set. 2014, p. 883-908. Disponível em: $<$ http://www.scielo.br/scielo.php?script $=$ sci arttext\&pid $=$ S010173302014000300883\&lng=en\&nrm=is $>$. Acesso 03 dez. 2018.

CIAVATTA, Maria. A produção do conhecimento sobre a configuração do campo da educação profissional e tecnológica. Holos, ano 32, v. 6, 2016, p. 33-49. Disponível em: $<$ http://www2.ifrn.edu.br/ojs/index.php/HOLOS/article/view/5013/1567. Acesso 03 dez. 2017>. Acesso 03 dez. 2017.

CEZAR, Taise Tadielo; FERREIRA, Liliana Soares. A relação entre educação e trabalho: um contexto de contradições e a aproximação com a educação profissional. Rev. Íbero-Americana de Estudos em Educação, v. 11, n. 4, 2016, p. 2141-2158. Disponível em:

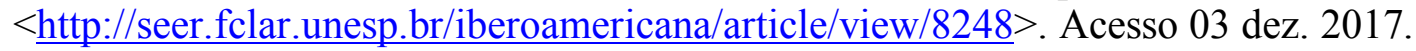

CRUZ, Shirleide Pereira da Silva; VITAL, Tainara Rayanne da Silveira. A construção da profissionalidade docente para a educação profissional: análise de concursos públicos para docente. Holos, ano 30, v. 2, 2014, p. 37-46. Disponível em: $<$ http://www2.ifrn.edu.br/ojs/index.php/HOLOS/article/view/1999/801>. Acesso 03 dez. 2017.

FARTES, Vera; SANTOS, Adriana Paula Q. Oliveira. Saberes, identidades, autonomia na cultura docente da educação profissional e tecnológica. Cadernos de Pesquisa, v. 41, n. 143, mai./ago. 2011, p. 376-401. Disponível em: $<$ http://www.scielo.br/pdf/cp/v41n143/a04v41n143.pdf $>$. Acesso 03 dez. 2017.

FAZENDA, Ivani C. A. Dificuldades comuns entre os que pesquisam educação. In: FAZENDA, Ivani C. A. (Org.). Metodologia da pesquisa educacional. 6.ed. São Paulo: Cortez Editora, 2000.

FERRARI, Mari. A internacionalização dos Institutos Federais: um estudo sobre o acordo BrasilCanadá. Educação e Sociedade, v. 6, n. 133, out./dez. 2015, p. 1003-1019. Disponível em: $<$ http://www.scielo.br/pdf/es/v36n133/1678-4626-es-36-133-01003.pdf $>$. Acesso 03 dez. 2017.

FERRETI, Celso João. Problemas institucionais e pedagógicos na implantação da reforma curricular da Educação Profissional técnica de nível médio no IFSP. Educação e Sociedade, v. 32, n. 116, jul./set. 2011, p. 789-806. Disponível em: <http://www.scielo.br/pdf/es/v32n116/a10v32n116.pdf $>$. Acesso 03 dez. 2017.

. Reformulações do Ensino Médio. Holos, ano 32, v. 6, 2016, p. 71-91. Disponível em:

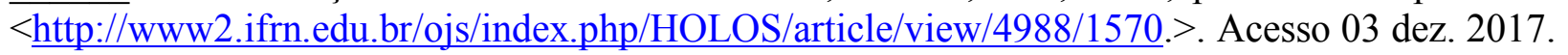

FOLGADO, Rosilane Meneses et al. Interdisciplinaridade, interculturalidade e intersetorialidade: princípios e aplicação no programa nacional de acesso ao ensino técnico e emprego (PRONATEC). Holos, ano 30, v. 4, 2014, p. 438-449. Disponível em: $<$ http://www2.ifrn.edu.br/ojs/index.php/HOLOS/article/view/2156>. Acesso 03 dez. 2017. 
FREITAS, Josí Aparecida de; OLIVEIRA, Cláudio José de. A produção de subjetividades docentes na educação profissional e tecnológica: em ação o dispositivo currículo. Revista Eletrônica de Educação, v. 9, n. 3, p. 281-291, 2015. Disponível em: $<$ http://www.reveduc.ufscar.br/index.php/reveduc/article/viewFile/1236/450>. Acesso 30 dez. 2017.

FRIGOTTO, Gaudêncio. A polissemia da categoria trabalho e a batalha das ideias nas sociedades de classe. Revista brasileira de Educação, v. 14, n. 40, jan./abr. 2009, p. 168-194. Disponível em: $<$ http://www.scielo.br/scielo.php?pid=S1413-24782009000100014\&script=sci abstract\&tlng $=$ pt $>$. Acesso 11 nov. 2017.

FRIGOTTO, Gaudêncio; CIAVATTA, Maria; RAMOS, Marise. Apresentação. In: RAMOS, Marise N. (Org.); FRIGOTTO, Gaudêncio (Org.); CIAVATTA, Maria (Org.). Ensino Médio Integrado: Concepção e Contradições. 3.ed. São Paulo: Cortez, 2012b. p. 7 - 20.

A gênese do Decreto n.5.154/2004: um debate no contexto controverso da democracia restrita. In: RAMOS, Marise N. (Org.); FRIGOTTO, Gaudêncio (Org.); CIAVATTA, Maria (Org.). Ensino Médio Integrado: Concepção e Contradições. 3.ed. São Paulo: Cortez, 2012a. p. 21-56.

GANDRA, Lucas Pereira; FIGUEIREDO, Carlos Vinícius da Silva. Formação de professores/educação profisssional: o perfil do docente ingressante no IFMS câmpus Coxim. Holos, ano 30, $\quad$ v. 2, 2014, p. 47-56. Disponível em: $<$ http://www2.ifrn.edu.br/ojs/index.php/HOLOS/article/view/1992/802>. Acesso 03 dez. 2017.

GARIGLIO, José Ângelo; BURNIER, Suzana. Saberes da docência na educação profissional e tecnológica: um estudo sobre o olhar dos professores. Educação em Revista, v. 28, n. 1, 2012, p. 211-236. Disponível em: $<$ http://www.scielo.br/scielo.php?pid=S010246982012000100010\&script=sci_abstract\&tlng $=\mathrm{pt}>$. Acesso 03 dez. 2017.

GRAMSCI, Antônio. Os intelectuais e a organização da cultura. Tradução de Carlos Nelson Coutinho. 4.ed. Rio de Janeiro: Editora Civilização Brasileira, 1982.

IFG. Plano de Desenvolvimento Institucional 2012-2016, 2012. Disponível em: $<$ https://www.ifg.edu.br/attachments/article/122/pdi.pdf> $>$. Acesso: 21 set. 2017.

LIMA, Erika Silva; SILVA, Francisca Natália da; SILVA, Lenina Lopes Soares. Educação Profissional para os jovens nas políticas educacionais da $1^{\text {a }}$ década do século XXI. Holos, ano 31, v. 4, 2015, p. 119-129. Disponível em:

$<$ http://www2.ifrn.edu.br/ojs/index.php/HOLOS/article/viewFile/3185/1131>. Acesso 03 dez. 2017.

LIMA, Fernanda Bartoly Gonçalves; SILVA, Kátia Augusta. A concepção de professores nos institutos federais: um estudo dos discursos políticos. Holos, ano30, v. 2, 2014, p. 3-12. Disponível em: $<$ http://www2.ifrn.edu.br/ojs/index.php/HOLOS/article/view/1987>. Acesso 03 dez. 2017.

LIMA JUNIOR, Agnaldo Mesquisa de; TAUCHEN, Gionara. Da educação integral ao Programa

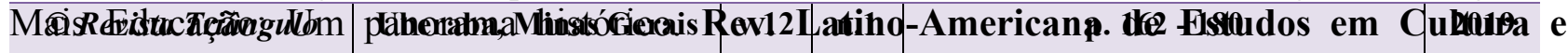


Sociedade, v. 2, ed. especial, p. 283-300, 2016. Disponível em: $<$ http://periodicos.claec.org/index.php/relacult/article/view/371>. Acesso 03 dez. 2017.

LUDKE, Menga; ANDRÉ, Marli E. D. A. Pesquisa em educação: abordagens qualitativas. São Paulo: EPU, 1986.

MACHADO, Lucília Regina de Souza. O desafio da formação dos professores para EPT e PROEJA. Educação e Sociedade, v. 32, n. 116, jul./set. 2011a, p. 689-704. Disponível em: $<$ http://www.scielo.br/pdf/es/v32n116/a05v32n116.pdf>. Acesso 03 dez. 2017.

. Saberes profissionais nos planos de desenvolvimento de institutos federais de educação. Cadernos de Pesquisa, v. 41, n. 143, mai./ago. 2011b, p. 352-375. Disponível em: $<$ http://www.scielo.br/pdf/cp/v41n143/a03v41n143.pdf>. Acesso 03 dez. 2017.

MANACORDA, Mario Aligheiro. Marx e a pedagogia moderna. Tradução Newton Ramos de Oliveira. Campinas: Editora Alínea, 2007.

MARX, Karl. O Capital: Crítica da Economia Política. Livro primeiro, tomo 1. São Paulo: Nova Cultural, 1996.

MARX, Karl; ENGELS, Friedrich. Manifesto do partido comunista. 1.ed. São Paulo: Expressão Popular, 2008.

MEDEIROS NETA, Olívia Moraes. A configuração do campo da educação profissional no Brasil. Holos, ano 32, v. 6, 2016, p. 50-55. Disponível em: $<$ http://www2.ifrn.edu.br/ojs/index.php/HOLOS/article/view/4947/pdf $>$. Acesso 21 nov. 2017.

MELO, Ticiane Gonçalves Sousa de; MOURA, Dante Henrique. Programa nacional de acesso ao ensino técnico e emprego (PRONATEC): expansão e privatização da educação profissional. Holos, ano 32, v. 6, 2016, p. 103-119. Disponível em: $<$ http://www2.ifrn.edu.br/ojs/index.php/HOLOS/article/view/4995>. Acesso 03 dez. 2017.

MIRANDA, Flavine Assis de. Desigualdade social e dualidade escolar: os programas de aceleração da aprendizagem e a escola unitária em Gramsci. Política e Gestão Educacional, n. 4, 2007. Disponível em: < http://seer.fclar.unesp.br/rpge/article/view/9149>. Acesso 03 dez. 2017.

MOURA, Dante Henrique. Educação Básica e Educação Profissional e Tecnológica: dualidade histórica e perspectivas e integração. Holos, Ano 23, Vol. 2, 2007, p. 4-30. Disponível em:

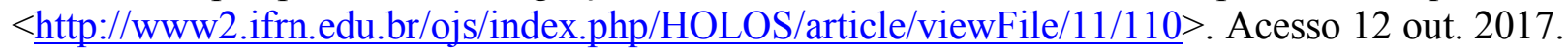

. Ensino médio integrado: Subsunção aos interesses do capital ou travessia para a formação humana integral?. Educação e Pesquisa, v. 39, n. 3, jul./set. 2013, p. 705-720. Disponível em: $<$ http://www.scielo.br/pdf/ep/v39n3/10.pdf $>$. Acesso 03 dez. 2017.

NEIVA FILHO, Daniel Martins; VASCONCELLOS, Carlos Alexandre Bastos de; SOUZA, Rodrigo Otávio Lopes de. Políticas públicas em educação profissional tecnológica: um foco na formação do

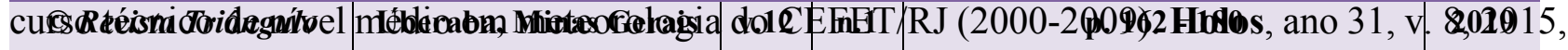


p. 304-313. Disponível em: <http://www2.ifrn.edu.br/ojs/index.php/HOLOS/article/view/2609>. Acesso 03 dez. 2017.

OLIVEIRA, Maria Rita Neto Sales. A formação de professores para a educação profissional e o plano nacional de educação (PNE): quais as perspectivas?. Holos, ano 32, v. 6, 2016, p. 145-155. Disponível em:

$<$ http://www2.ifrn.edu.br/ojs/index.php/HOLOS/article/view/4987>. Acesso 03 dez. 2017.

OLIVEIRA, Adriana Peixoto de; MATTA, Ludmila Gonçalves da. Os conflitos entre os diferentes projetos de sociedade e os impactos na educação profissional tecnológica (EPT). Rev. Bras. Planej. Desenv, v. 6, n. 2, 2017, p. 234-249. Disponível em: $<$ https://periodicos.utfpr.edu.br/rbpd/article/view/5770>. Acesso 03 dez. 2017.

PAULO NETTO, José. Introdução ao estudo do método de Marx. 1.ed. São Paulo: Expressão Popular, 2011.

PEREIRA, Ulisséia Ávila; FRANÇA, Magna. Novas diretrizes educacionais e novos projetos pedagógicos - (ETFRN e CEFET-RN): entre o pensar e o fazer. Holos, ano 31, v. 6, 2015, p. 328337. Disponível em:

$<$ http://www2.ifrn.edu.br/ojs/index.php/HOLOS/article/view/3351>. Acesso 03 dez. 2017.

RAMOS, Marise Nogueira. A educação da classe trabalhadora e o PNE (2014-2024). Holos, ano 32, v. 6, 2016, p. 3-21. Disponível em:

$<$ http://www2.ifrn.edu.br/ojs/index.php/HOLOS/article/view/4982>. Acesso 03 dez. 2017.

Concepção do ensino médio integrado. In: ARAÚJO, Ronaldo. TEODORO, Elinilze. (Org.).

Ensino Médio Integrado no Pará como Política Pública. Belém: SEDUC-PA, 2009, p. 144-182.

RIBEIRO, Tarcísio Araujo Kuhn. De qual formação profissional estamos falando? Uma questão colocada aos institutos federais. Revista Eixo, v. 1, n. 2, 2012, p. 20-29. Disponível em: $<$ http://revistaeixo.ifb.edu.br/index.php/RevistaEixo/article/view/63/33 $>$. Acesso 03 dez. 2017.

RODRIGUES, Marcela Rubim Schwab Leite. Formar-se para ensinar na educação profissional, científica e tecnológica: experiência de um Instituto Federal. Revista Eventos Pedagógicos, v. 7, n. 2, 2016, p. 617-619. Disponível em: $<$ http://sinop.unemat.br/projetos/revista/index.php/eventos/article/view/2080/1760. $>$ Acesso 03 dez. 2017.

SÁNCHEZ GAMBOA, Silvio. Pesquisa em educação: métodos e epistemologias. 2.ed. Chapecó: Argos, 2012.

SAVIANI, Dermeval. Trabalho e educação: fundamentos ontológicos e históricos. Revista Brasileira de Educação, v. 2, n. 34, jan./abr. 2007, p. 152-180. Disponível em:

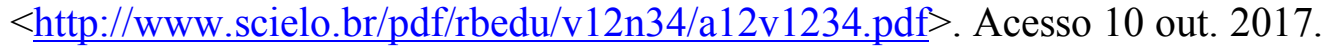


SAVIANI, Dermeval. O choque teórico da politecnia. Trabalho, educação e saúde, v. 1, n. 1, mar./ago. 2003, p. 131-152. Disponível em: <http:/www.scielo.br/scielo.php?pid=S1981-

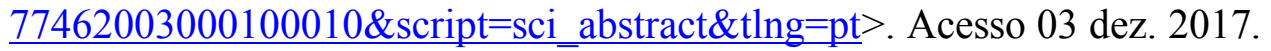

SEVERINO, Antônio Joaquim. Metodologia do trabalho científico. 23.ed. São Paulo: Editora Cortez, 2007.

SHIROMA, Eneida Oto; LIMA FILHO, Domingos Leite. Trabalho docente na educação profissional e tecnológica e no PROEJA. Educação e Sociedade, v. 32, n. 116, jul./set. 2011, p. 725-743. Disponível em: $<$ http://www.scielo.br/pdf/es/v32n116/a07v32n116.pdf $>$. Acesso 03 dez. 2017.

SILVA, Filomena Lucia Gossler Rodrigues. Plano nacional de educação e seus desdobramentos sobre as novas diretrizes para a formação de professores da educação profissional: identidades profissionais em construção. Holos, ano 32, v. 6, 2016, p. 156-177. Disponível em: <http://www2.ifrn.edu.br/ojs/index.php/HOLOS/article/view/4986/1575>. Acesso 03 dez. 2017.

SILVA, Jose Moises; CABRAL NETO, Antonio. Concepções de formação profissional técnica de nível médio adotadas pelo IFRN especificidades e (des)continuidades. Holos, ano 31, v. 5, 2015, p. 201-212.

Disponível

em: $<$ http://www2.ifrn.edu.br/ojs/index.php/HOLOS/article/viewFile/3315/1158>. Acesso 03 dez. 2017.

TRIVIÑOS, Augusto N. S. Introdução à pesquisa em ciências sociais: a pesquisa qualitativa em educação. São Paulo: Atlas, 1987.

VIEIRA, M. S. O. C.; GOMES, D. C.; SILVA, J. M. T. O papel do Instituto Federal de Educação, Ciência e tecnologia (IFRN) para a qualificação e empregabilidade: um estudo dos egressos do curso de informática do IFRN em Currais Novos/RN. Holos, ano 27, v. 1, 2011, p. 168-181. Disponível em:

$<\underline{\text { http://www2.ifrn.edu.br/ojs/index.php/HOLOS/article/view/514.> }}$

Acesso em 31 dez. 2017.

ZATTI, Vicente; DONNER, Sandra Cristina; JESUS, Edson Regis. Fundamentos filosóficohistóricos da proposta dos institutos federais de educação. Holos, ano 30, v. 2, 2014, p. 57-64. Disponível em: $<$ http://www2.ifrn.edu.br/ojs/index.php/HOLOS/article/view/1988/803>. Acesso 03 dez. 2017.

\begin{tabular}{|r|r|}
\hline & Recebido em: 4 Fev. 2018 \\
\cline { 2 - 2 } & Aprovado em: 18 Abr. 2019 \\
\hline
\end{tabular}

